\title{
Terapi Hipertensi di Rumah dengan Terapi Komplementer
}

\author{
Miko Eka Putri ${ }^{1}$, Nurfitriani ${ }^{2}$ \\ Program studi S 1 Keperawatan ${ }^{1,}$ Program studi D III Keperawatan ${ }^{2}$ \\ email: putri29iwan@gmail.com
}

Submitted : 09/12/2019

Accepted: 17/12/2019

Published: $31 / 01 / 2020$

\begin{abstract}
Based on data from the 5 biggest diseases in Jambi Province, which were reported by the Jambi Provincial Health Office from 2014 to 2016, showed that hypertension was ranked 2nd out of 5 biggest diseases in Jambi Province. Seen from the prevalence of hypertension, it shows an increase from 12.16\% in 2014 to 13.69\% in 2016. The incidence rate of Putri Ayu Health Center is quite high as 3334 sufferers in 2017. This community service is done to help the community, especially hypertension sufferers to overcome hypertension problems with complementary therapy. This service is carried out with 4 implementation processes starting from 1) measuring blood pressure, 2) conducting health education about the treatment of hypertension with complementary therapy by progressive muscle relaxation, 3) evaluating the results of activities. This dedication was assisted by 1 lecturer and 2 students. After progressive muscle relaxation training exercises, blood pressure measurements are taken again. The results showed that $25 \%$ of participants who had not decreased blood pressure.
\end{abstract}

Keyword: complementary therapy, hypertention, relaksasi otot progresif

\begin{abstract}
Abstrak
Berdasarkan data 5 penyakit terbesar di Provinsi Jambi yang dilaporkan oleh Dinas Kesehatan Provinsi Jambi mulai tahun 2014 sampai dengan 2016 menunjukkan bahwa penyakit hipertensi menduduki urutan ke 2 dari 5 penyakit terbesar di Provinsi Jambi. Dilihat dari angka prevalensi kejadian Hipertensi menunjukkan peningkatan dari 12,16\% pada tahun 2014 menjadi 13,69\% pada tahun 2016. Angka kejadian Puskesmas Putri Ayu cukup tinggi sebanyak 3334 penderita tahun 2017. Pengabdian Masyarakat ini dilakukan untuk membantu masyarakat terutama penderita hipertensi untuk mengatasi masalah hipertensi dengan terapi komplementer, dilakukan dengan 4 proses pelaksanaan mulai dari 1) melakukan pengukuran tekanan darah, 2) melakukan penyuluhan kesehatan tentang perawatan hipertensi dengan terapi komplementer dengan relaksasi otot progresif, 3) melakukan evaluasi hasil kegiatan. Pengabdian kepada masyarakat ini dibantu oleh 2 orang mahasiswa. Hasil yang diperoleh setelah dilakukan latihan tekhnik relaksasi otot progresif, selanjutnya dilakukan pengukuran kembali tekanan darah menunjukkan bahwa $25 \%$ peserta yang belum terjadi penurunan tekanan darah.
\end{abstract}

Kata Kunci : hipertensi, relaksasi otot progresif, terapi komplementar

\section{PENDAHULUAN}

Hipertensi merupakan peningkatan tekanan darah sistolik lebih dari $140 \mathrm{mmHg}$ dan tekanan diastolik lebih dari $90 \mathrm{mmHg}$ (Brunner \& Suddarth, 2013).Menurut WHO (2014), Hipertensi adalah tekanan darah sistole $\geq 140 \mathrm{mmHg}$ dan tekanan darah diastole $\geq 90 \mathrm{mmHg}$.Hipertensi merupakan masalah kesehatan global yang membutuhkan perhatian karena dapat menyebabkan kematian utama di negara maju maupun berkembang.Berdasarkan data dari World Health Organization (WHO) tahun 2013 diketahui bahwa hipertensi sering menimbulkan penyakit kardiovaskuler, ginjal dan stroke. Telah terdapat 9,4 juta orang dari 1 milyar orang didunia meninggal akibat gangguan kardiovaskuler. Prevalensi hipertensi masih tergolong tinggi, di negara maju prevalensi hiperensi sebesar 35\% dari populasi dewasa dan di negara berkembang prevalensi 
hipertensi sebesar $40 \%$ dari populasi dewasa.

Hasil Riset Kesehatan Dasar di seluruh Provinsi di Indonesia yang didapat melalui pengukuran pada umur $>18$ tahun sebesar $25,8 \%$, tertinggi dibangka Belitung $(30,9 \%)$, Kalimantan $(30,8 \%)$, Kalimantan Timur $(29,6 \%)$ dan Jawa Barat $(29,4 \%)$. Prevalensi hipertensi di Indonesia yang didapat melalui kuesioner terdiagnosis tenaga kesehatan sebesar 9,4\%, yang didiagnosis tenaga kesehatan atau sedang minum obat sebesar $9,5 \%$. Jadi, ada $0,1 \%$ yang minum obat sendiri. Responden yang mempunyai tekanan darah normal tetapi sedang minum obathipertensi sebesar $0,7 \%$. Jadi prevalensi hipertensi di Indonesia sebesar 26,5\% $(25,8 \%+0,7 \%)$. Hipertensi terlihat meningkat dengan bertambahnya umur dan hipertensi pada perempuan lebih cenderung lebih tinggi dari pada laki-laki (Riskesdas, 2013).

$$
\text { Adapun Riskesdas }
$$

melaporkan bahwa di Indonesia prevalensi hipertensi berdasarkan hasil pengukuran pada penduduk umur $\geq 18$ tahun mengalami peningkatan yaitu $25,8 \%$ di tahun 2013 menjadi $34,1 \%$ pada tahun 2018. Sedangkan di Provinsi Jambi angka hipertensi mencapai 30,2\% di tahun 2013 dan meningkat hingga 32,8\% di tahun 2018. Banyaknya penderita hipertensi diperkirakan sebesar 15 juta bangsa Indonesia tetapi hanya $4 \%$ yang mampu mengendalikan hipertensi (controlled hypertension). (Bustan, 2015 dalam Putri, 2019)

Berdasarkan data 5 penyakit terbesar di Provinsi Jambi yang dilaporkan oleh Dinas Kesehatan Provinsi Jambi mulai tahun 2014 sampai dengan 2016 menunjukkan bahwa penyakit hipertensi menduduki urutan ke 2 dari 5 penyakit terbesar di Provinsi Jambi. Dilihat dari angka prevalensi kejadian Hipertensi menunjukkan peningkatan dari $12,16 \%$ pada tahun 2014 menjadi 13,69 \% pada tahun 2016. Angka kejadian Puskesmas
Putri Ayu cukup tinggi sebanyak 3334 penderita tahun 2017.

Banyak faktor yang meyebabkan terjadinya hipertensi. Adapun faktor yang mempengaruhi tekanan darah seperti; usia, stress, etnik, jenis kelamin, variasi harian, obat-obatan, aktivitas, berat badan, dan merokok ( Kozier,et al, 2010). Hipertensi yang dialami penderitanya yang terus menerus dan tidak diatasi dapat mengakibatkan banyak hal kesehatan terutama terjadi perdarahan pada otak atau sering disebut stoke yang bahkan dapat mengakibatkan kematian. agar tidak terjadi masalah kesehatan yang fatal, maka penderita hipertensi harus dirawat dirumah. Salah satu cara perawatan dirumah adalah dengan pengobatan herbal. Berdasarkan hal tersebut, maka perlu dilakukan pemeriksaan tekanan darah dan penyuluhan tentang hipertensi di wilayah Kelurahan Murni.

Hipertensi bukan hanya penyakit biasa. Bahaya hipertensi bisa dirasakan oleh masyarakat karena kurang pengetahuan keluarga dalam merawat anggoita keluarga yang sakit. Kelurahan murni merupakan wilayah kerja puskesmas. Tingginya angka kejadi hipertensi yang mencapai 3334 penderita di wilayah kerja puskesmas Putri Ayu perlu penangan khusus untuk mengatasi masalah kesehatan terkait dengan hipertensi . pentingnya kegiatan ini dalam membantu masyarakat untuk menyelesaikan masalah kesehatan keluarga demi meningkatkan derajat kesehatan masyarakat keluarahan murni pada khususnya dan masyarakat Indonesia umumnya.

Salah satu tehnik untuk menurunkan tekanan darah adalah dengan terapi relaksasi. Terapi relaksasi otot progresif dapat meningkatkan relaksasi dengan menurunkan aktivitas saraf simpatis dan meningkatkan aktivitas saraf parasimpatis sehingga terjadi vasodilatasi diameter arteriol. Saraf parasimpatis akan melepaskan asetilkolin untuk menghambat aktivitas saraf simpatis dengan menurunkan 
kontraktilitas otot jantung, vasodilatasi arteriol dan vena (Muttaqin, 2014 dalam Ilham dkk, 2019). Kegiatan ini juga telah dilakukan oleh Kadri dkk, 2019, tentang Penerapan Teknik relaksasi otot progresif pada penderita hipertensi. Yang dilakukan di ruang aula PSTW Budi Luhur Kota Jambi pada tahun 2018, hasil yang diperoleh $85 \%$ peserta mampu memahami tentang materi yang disampaikan.

\section{TARGET DAN LUARAN \\ Target}

Demi meningkatkan derajat kesehatan masyarakat Indonesia khususnya masyarakat di RT 17 kelurahan murni , maka perlu adanya peran petugas kesehatan terutama perawat dalam menyelesaikan permasalahan yang ada di masyarakat terutama masalah hipertensi. Agar masalah hipertensi yang ada di masyarakat RT 17 kelurahan murni ini dapat diatasi, maka perlu dilakukan pemeriksaan tekanan darah secara rutin dan pemberian pendidikan kesehatan dengan terapi komplementer untuk mengatasi hipertensi. Kegiatan ini bertujuan untuk membantu masyarakat merawat anggota keluarga yang sakit dengan hipertensi di rumah melalui pendidikan kesehatan dan latihan relaksasi otot progresif.

\section{Luaran}

Adapun Target Luaran dalam kegiatan ini adalah :

1. Teridentifikasi masyarakat yang ada pada penderita hipertensi

2. Meningkatnya pengetahuan Masyarakat tentang bahaya hipertensi

3. Terlaksananya kegiatan pemeriksaan tekanan darah gratis.

4. Terlaksananya kegiatan penyuluhan tentang hipertensi

5. Terlatihnya penderita hipertensi dalam mengimplementasikan tekhnik relaksasi otot progresif

\section{METODE PELAKSANAAN}

Kegiatan pengabdian masyarakat ini dilaksanakan di bulan Maret s/d Agustus 2019. Adapun tahap pelaksanaan Pengabdian kepada masyarakat ini berupa:

1. Meminta izin pelaksanaan kegiatan Kelurahan dan Ketua RT

2. Meminta persetujuan dari Puskesmas Putri Ayu dan meminta data penderita hipertensi dari Puskesmas

3. Mengidentifikasi penderita hipertensi yang tinggal di wilayah kerja Puskesmas terutama di RT 11 Kelurahan Murni

4. Menyepakati bersama untuk kegiatan 45 menit kedepan

5. Melakukan pemeriksaan tekanan darah sebelum dilakukan penyuluhan dan latihan tekhnik relaksasi otot progresif

6. Melakukan Penyuluhan tentang perawatan hipertensi di rumah dengan terapi komplementer yaitu terapi tekhnik relaksasi otot progresif.

7. Melakukan evaluasi pengukuran tekanan darah setelah diberikan terapi relaksasi otot progresif

Metode pelaksanaan pengabdian ini adalah dengan metode pemberian pendidikan kesehatan atau penyuluhan kepada penderita hipertensi serta mamberikan terapi latihan relaksasi otot progrsif. Adapun rangkaian kegiatan yang dilakukan adalah sebagai berikut:

1. Melakukan pemeriksaan tekanan darah

2. Melakukan penyuluhan kepada masyarakat

3. Melatih peserta untuk melakukan latihan relaksasi otot progresif

4. Melakukan evaluasi kegiatan

\section{HASIL DAN PEMBAHASAN}

Pengabdian masyarakat ini bertujuan memberikan pengetahuan dan latihan relaksasi otot progresif pada peserta penderita hipertensi. Penyuluhan dilakukan di kelas PAUD. Kondisi ruangan memang belum dapat dikatakan kondusif untuk pelaksanaan penyuluhan dan latihan 
relaksasi otot progresif. Mengingat tempat yang tidak ada selain kelas Paud tersebut, sehingga pelaksanaan dilaksanakan dengan kondisi yang kurang kondusif tersebut. Sebelum pelaksanaan penyuluhan masingmasing peserta telah dilakukan pemerikasaan tekanan darah. Hanya 1 orang yang kondisi tekanan darahnya dalam kondisi normal yaitu 120/80 mmhg. Sebanak 19 orang peserta lainnya memiliki tekanan darah lebih dari 130 untuk sistole dan lebih dari 90 untuk diastole.

Selama pelaksanaan berlangsung rata- rata peserta mengajukan pertanyaan. jumlah peserta penyuluhan tersebut berjumlah 20 orang. Peserta sangat antusias sekali dalam mendengarkan penyuluhan. Dari 20 peserta penyuluhan, hampir seluruhnya bertanya tentang hipertensi dan penatalaksanaannya. Selama proses penyuluhan tidak ada peserta yang minta izin untuk keluar dari ruangan.

Setelah penyuluhan 30 menit penyuluhan dilakukan, selanjutnya adalah mengajarkan peserta latihan relaksasi otot progresif. Selama latihan relaksasi otot progresif, semua peserta dapat mengikuti dengan baik. Suasana selama latihan cukup dikondisikan senyaman mungkin. Pelaksanaan ini dibantu oleh mahasiswa STIKes Baiturrahim. Setelah dilakukan latihan tekhnik relaksasi otot progresif, selanjutnya dilakukan pengukuran kembali tekanan darah. Hasil menunjukkan bahwa $25 \%$ peserta yang belum terjadi penurunan tekanan darah.

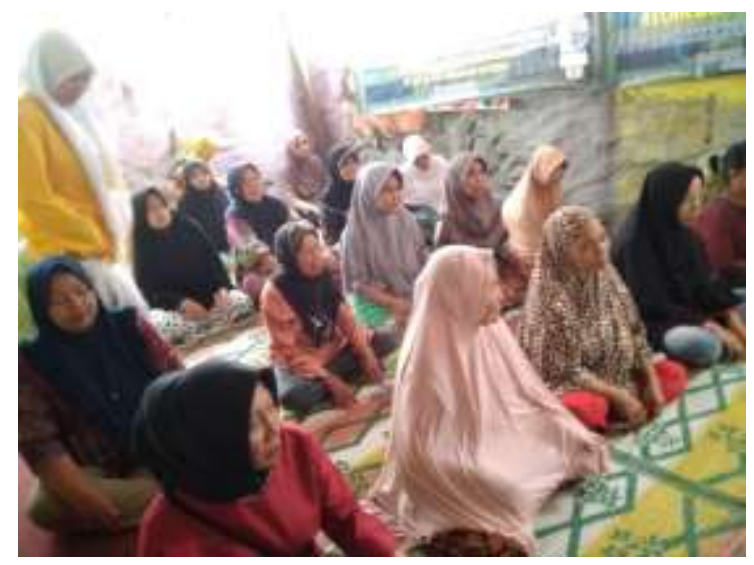

Gambar 1. Pelaksanaan Penyuluhan

Luaran yang dicapai setelah proses penyuluhan sebagian besar $85 \%$ peserta mampu menjawab pertanyaan dari moderator, setelah dilatih tekhnik relaksasi otot progresif, semua peserta mampu mengikuti instruksi dari instruktur. Evaluasi dari hasil proses kegiatan adalah peserta mampu mempraktikkan latihan tekhnik relaksasi otot progresif.

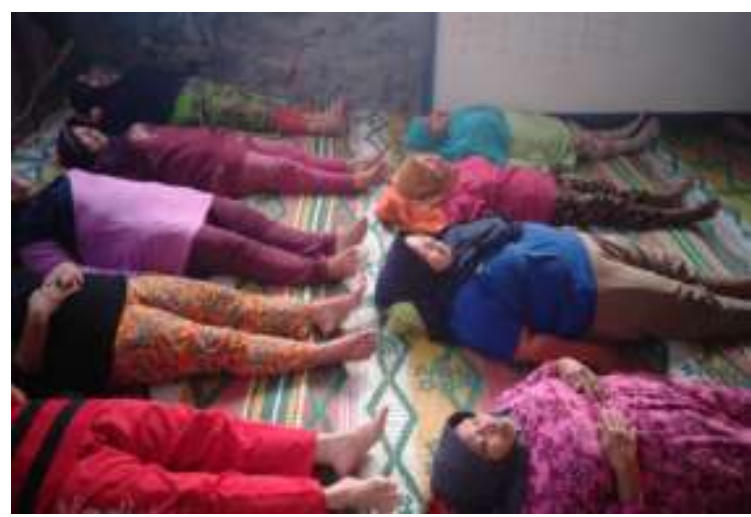

Gambar 2. Latihan Relaksasi otot Progresif

\section{KESIMPULAN DAN SARAN}

\section{A. Kesimpulan}

Dengan adanya pengabdian masyarakat di RT 17 kelurahan Murni ini, semua peserta yang menderita hipertensi sebanyak 20 orang mengikuti kegiatan penyuluhan dan latihan relaksasi otot progresif dengan harapan dapat dilakukan secara mandiri nantinya walaupun hasilnya $25 \%$ penderita setelah pelatihan relaksasi otot progresif belum mengalami penurunan.

\section{B. Saran}

1. Bagi Posyandu Lansia di RT 11 Kelurahan Murni

Diharapkan puskesmas menjadikan program terapi komplementer dengan relaksasi otot progresif sebagai program rutin posyandu lansia untuk penderita hipertensi.

2. Bagi Insitusi STIKes Baiturrahim

Diharapkan STIKes Baiturrahim terus meningkatkan keikutsertaan dosen dalam pengabdian kepada masarakat dalam bentuk terapi komplementer untuk 
memandirikan masyarakat RT 11 Hidayat A Aziz Alimul. 2009.

kelurahan Murni secara berkelanjutan.

\section{UCAPAN TERIMAKASIH}

Terimakasih kepada STIKes Baiturrahim dan kepada Ketua RT 11 serta bapak Lurah kelurahan Murni Kecamatan Danau Sipin Jambi yang telah memfasilitasi kegiatan pengabdian kepada masyarakat ini.

\section{DAFTAR PUSTAKA}

Aspiani Reni Yuli. 2014. Buku Ajar Asuhan Keperawatan Klien Gangguan Kardiovaskular. Jakarta : ECG

Brunner \& Suddart. 2013. Keperawatan Medikal Bedah. Edisi 12.Jakarta Penerbit Buku Kedokteran EGC.

Depkes RI. 2013. Riset Kesehatan Dasar 2013.Jakarta: Badan Penelitian dan Pengembangan Kesehatan Kementrian Kesehatan RI.

Dinas Kesehatan Provinsi Jambi. 2016. Profil Kesehatan Jambi 2015.Jambi.

Dinas Kesehatan Provinsi Jambi. 2017. Profil Kesehatan Jambi 2016. Jambi.

Dinas Kesehatan Kota Jambi. 2018. Data Penderita Hipertensi Di Seluruh Puskesmas yang Berada di Kota Jambi Tahun Anggaran 2016-2017. Jambi

Divine gan G. 2012.Program Olahraga Tekanan Darah Tinggi.Jakarta : Citra Aji Parama

Fatmah.2010. Gizi Lanjut Usia. Depok : Erlangga.

H Kadri, S Fitrianti, 2019, Penatalaksanaan Hipertensi Dengan Relaksasi Otot Progresif Pada Lansia Di Panti Sosial Tresna Werdha Budi Luhur Kota Jambi. Jurnal Abdimas Kesehatan (JAK) 1 (2), 138-142

Hidayat A Aziz Alimul. 2009. Kebutuhan Dasar Manusia. Jilid 1.Jakarta : Salemba Medika.
Konsep Dasar Keperawatan. Edisi 2.Jakarta : Salemba Medika.

Kozier, et al. 2010.Buku Ajar Fundamental Keperawatan.Edisi 7.Vol 1.Jakarta :Penerbit Buku Kedokteran EGC.

Kozier, et al. 2010. Buku Ajar Fundamental Keperawatan.Edisi 7. Vol II.Jakarta :Penerbit Buku Kedokteran EGC.

Kurniadi Helmanu \& Nurrahmani.(2015). Stop Diabetes Hipertensi Kolestrol Tinggi Jantung Koroner.Yogyakarta : Istana Media

Lestari, T. 2015. Kumpulan Teori Untuk Kajian Pustaka Penelitian Kesehatan. Nuha Medika : Yogyakarta

M Ilham, A Armina, H Kadri, 2019, Efektivitas Terapi Relaksasi Otot Progresif Dalam Menurunkan Hipertensi Pada Lansia. Jurnal Akademika Baiturrahim Jambi 8 (1), 58-65

VS Putri, M Maimaznah dkk, 2019, Penyuluhan Kesehatan Tentang Hipertensi Di Wilayah Rt 03 Kelurahan Murni , Jurnal Abdimas Kesehatan (JAK) 1 (3), 180-184 